\title{
Exploring the spatial tools to generate social inclusive \& empowered space for people living in margins. Subtitle
}

\author{
Charles PORWAL, DIT University, India
}

\begin{abstract}
A good public space must be accommodative for everyone including the marginal, the forgotten, the silent, and an undesirable people. With the process of development, the city leaves behind the marginalized section of the society especially urban poor, who constitute about 20-30 percent of the urban population and are majorly involved in informal settlement like congested housing typologies and informal economy in which they face the everyday social, physical and economic exclusion. Thus, the informal sector and the marginalized becomes the forgotten elements in urban space.
\end{abstract}

'Cities for the Citizen' a slogan described by Douglas address the same issues of democratization, multicultural/gender difference between humans. Though these people have strong characteristics and share a unique pattern and enhances the movement in the city which makes a city a dynamic entity. The lack of opportunities and participation to such section leaves the city divided and generates the negative impacts in the mind of victims which further leads to degradation of their mental health and city life because of their involvement in crime, unemployment, illiteracy and unwanted areas.

The physical, social, cultural and economic aspects of space should accommodate the essential requirements for the forgotten and provide them with inclusive public environment. It is very necessary that they generate the association and attachment to the place of their habitation. We can easily summarize that the city which used to be very dynamic and energetic is now facing the extreme silence in the present pandemic times. The same people are returning back to their homes after facing the similar problems of marginalization and exclusion even during hard times where they had no place to cover their heads. So, we have to find the way in which they can be put into consideration and make them more inclusive and self-sustaining.

With the economic stability, social stability is also equally necessary for the overall development of an individual. So, the paper tries to focus upon the idea of self-sustaining livelihood and social urbanism which talks about development of cities aiming to the social benefit and upliftment of their citizen. The social urbanism strategy in any project tries to inject investment into targeted areas in a way that cultivates civic pride, participation, and greater social impact. Thus, making the cities inclusive and interactive for all the development. The paper will tries to see such spaces as a potential investment in term of city's finances and spaces to generate a spatial \& development toolkit for making them inclusive by improving the interface of social infrastructure.

\section{Keywords}

Social infrastructure, social urbanism, inclusive development, urban rights, self-sustaining livelihood, marginalized people. 


\section{Introduction}

Cities have always been a place of attraction by inviting people to take the opportunity. Increasing urbanisation results in significant migration from small towns and villages, which mainly belong to weaker sectors of the economy. Ultimately, these migrants end up settling in the informal economy and informal settlements such as slums, making shift agreements because of social, cultural and economic instability. In physical exclusion, they undergo social, spatial and economic exclusion over time. It is very important to make them the part of the city by giving them hold of their basic city rights like access, opportunity and participation.
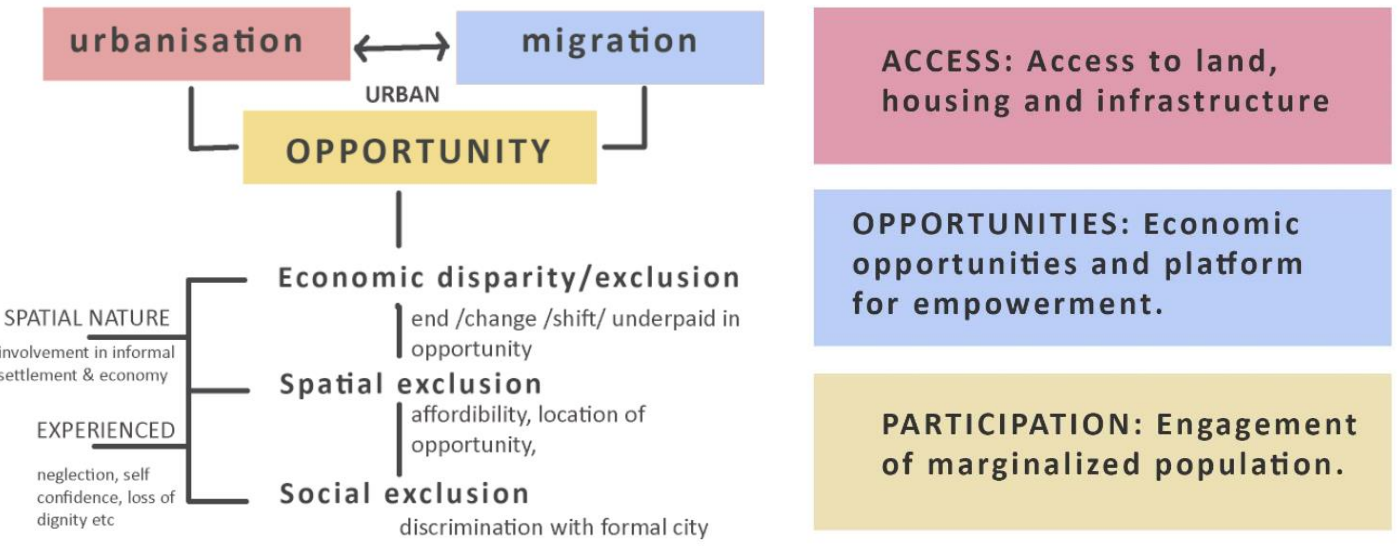

Figure 1 Types of exclusion faced by the margins and what right they look forward in the city.

Considering cities as reflections of broader economic and social forces, shifts in political and economic systems influence the evolution of the urban fabric. The effect of socialist philosophy on urban growth is discussed in this paper. One realised that a walk in a poor community, contact with the people, is not the charity they want, but rather a sense of acceptance, participation and integrity. Interestingly, Medellin in Columbia, Latin America gives us an example of how the basic human right of the poor is backed by an integrated planning approach that unites political will, government, civil society, architecture and design to turn the once 'abuse and drug wealth' into a transforming inclusive society-Dignity! The tool employed by Medellin was popularised as 'Social Urbanism'.

\subsection{Aims:}

To explore the spatial urban approaches for bringing the social inclusion and social transformation..

\subsection{Objectives:}

- To understand the various approaches to carry such social transformation.

- To analyze the transformation due to development at such areas.

- To categorizes the major components for the transformation.

- To understand the formal \& informal structure at the development.

\subsection{Methodology}

- Understanding the types, characteristics and pattern of exclusion towards marginalized people.

- Understanding these people interactions in urban environment.

- Taking learning from similar cases around the world.

- $\quad$ Live case study and documentation to understand the structure of their livelihood and habitation. 
- Generating a system and toolkit for improving their environment.

\subsection{LITERATURE REVIEW}

\section{Marxism}

As a theory, it relies on a method of socioeconomic analysis that views class relations and social conflict using a materialist interpretation of historical development and takes a dialectical view of social transformation. It originates from the works of 19th-century German philosophers Karl Marx and Friedrich Engels.

\section{Right to the City}

The right to the city is not intended to be interpreted as a civil right for people. It is also used as a social utopia and a collective assertion that encourages thoughts and proposals for a better society and progressive movements. It is a slogan for worldwide protests that struggle against the manifestations of many industrial cities in which municipal processes and utilities have been privatised and where prosperity is mainly guided by corporations, businesses and economies.

According to Harvey: "The Right to the city is far more than the individual liberty to access urban resources: it is a right to change ourselves by changing the city. It is, moreover, a common rather than an individual right since this transformation inevitably depends upon the exercise of a collective power to reshape the processes of urbanization. The freedom to make and remake our cities and ourselves is, I want to argue, one of the most precious yet most neglected of our human rights."

\section{Extract from cases study}

\subsection{Medellin, Columbia}

Medellin is Colombia's second largest city and has long maintained a high profile reputation for crime and drug activity. But with intensive public investment in infrastructure and urban regeneration, including transport, as well as services such as libraries and learning centers, Medellin was largely able to transform its global brand from a city of violence to a city of creativity and hope.

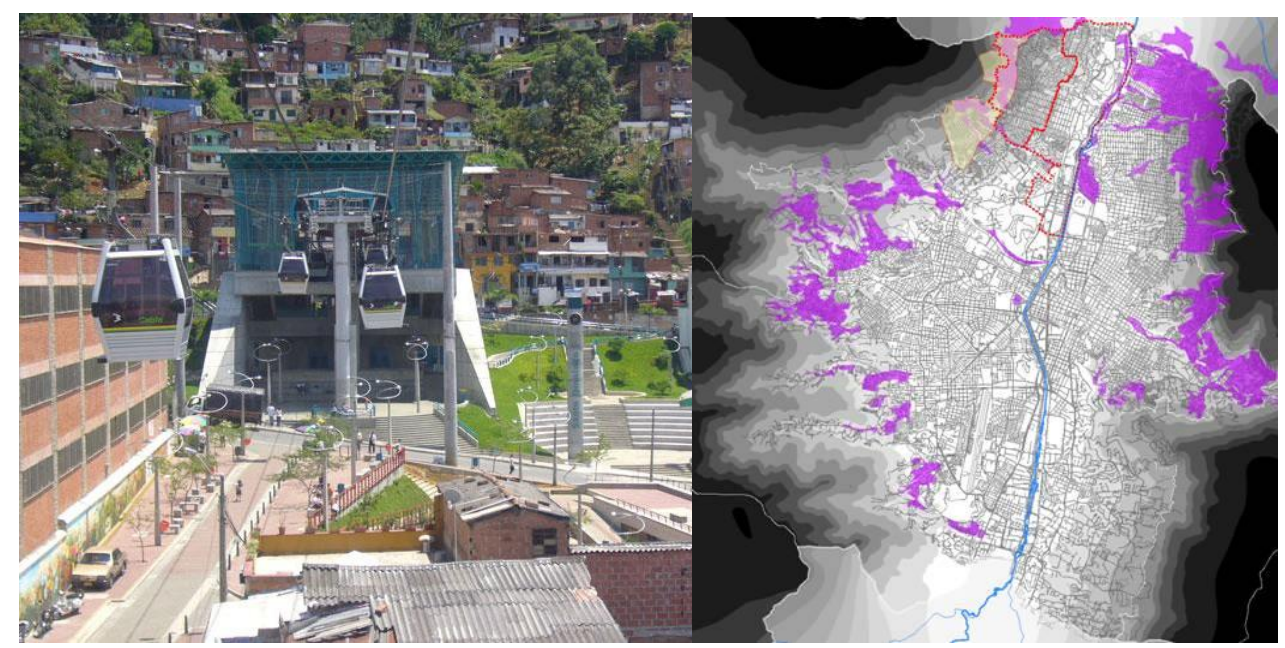

Figure 2 : Cable car Intervention done in Medellin to improve public mobility

Historically, the inhabitants of Medellin have been underserved by travel, urban spaces and social infrastructure, which have restricted their involvement in the formal sector and therefore have limited employment prospects, perpetuating cycles of hardship for the poorest residents. A culture of violence 
and chaos has been intertwined in these webs of informality, which gained Medellin a reputation as the world's most dangerous city in the 1990s.

The government focussed on three parameters to enter into the internal web and system of these settlement and generating a sense of citizenship in them by making them inclusive part of the development focussing on their social upliftment.

Mobility - The factor of mobility which focussed on connecting these people to the major city network. Also it provided the opportunity to the government to enter into the inaccessible areas which were nodes of illegal activites. The accessibilty measure opened up number of nodes for movement ans survillence.

Social Infrastructure - The investment in the social and institutional spaces like library, comunity space, parks near the cable car station helped people to access these places. The high quality architecture building in their places developed the sense of pride among the people.

Urban art - The Urban art helped to give an altogether different image to the neighbourhood spaces. The project of renewal of the local interface with few public amentities like benches, light poles, informal sitting spaces etc.. invited people to interact to the places which were previously dark and shady.

\subsection{Slum networking in Indore}

Slum networking in Indore is one of the initial project which focused on holistic approach by inviting the people to participation in the development program. The system strategized the method to come with solution to community based sanitation and environment improvement. The project focused on connecting all the slums settled around the river edges. The system worked very well as people were connected to basic services and community spaces.

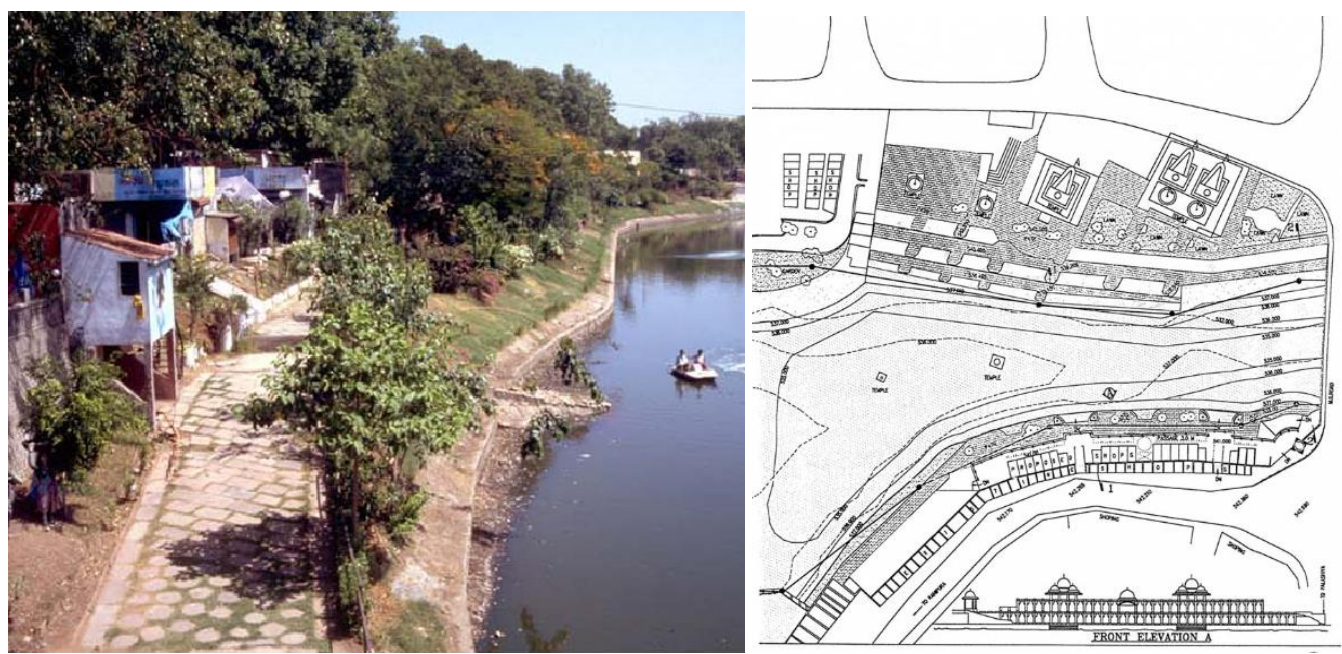

Figure 3 - Internal connected pathways along the river edge in Indore

The projects focused upon developing the 120 community spaces which incorporated the activities like education, health, women and youth empowerment to generate a system of connecting them to formal system. Similarly, the slum level infrastructure intervention proposed for providing basic services like sanitation, drainage, street lighting, water supply and road connection improvements through low cost innovative systems. 


\section{Live Case Study - Kanpur}

\subsection{Site delineation \& introduction}

The site is situated in the middle of the city, at the intersection between the old core area and the newly formed city region. The nearby site has substantial transport structures around it, i.e. the central station of Kanpur and ISBT which is $1.2 \mathrm{~km}$ apart from each other. It contains largest transit footfall of the people searching for opportunities from the nearby cities, towns and small towns. In addition, the site shares the two main road networks for the transportation of goods and cities that connect to the high state.

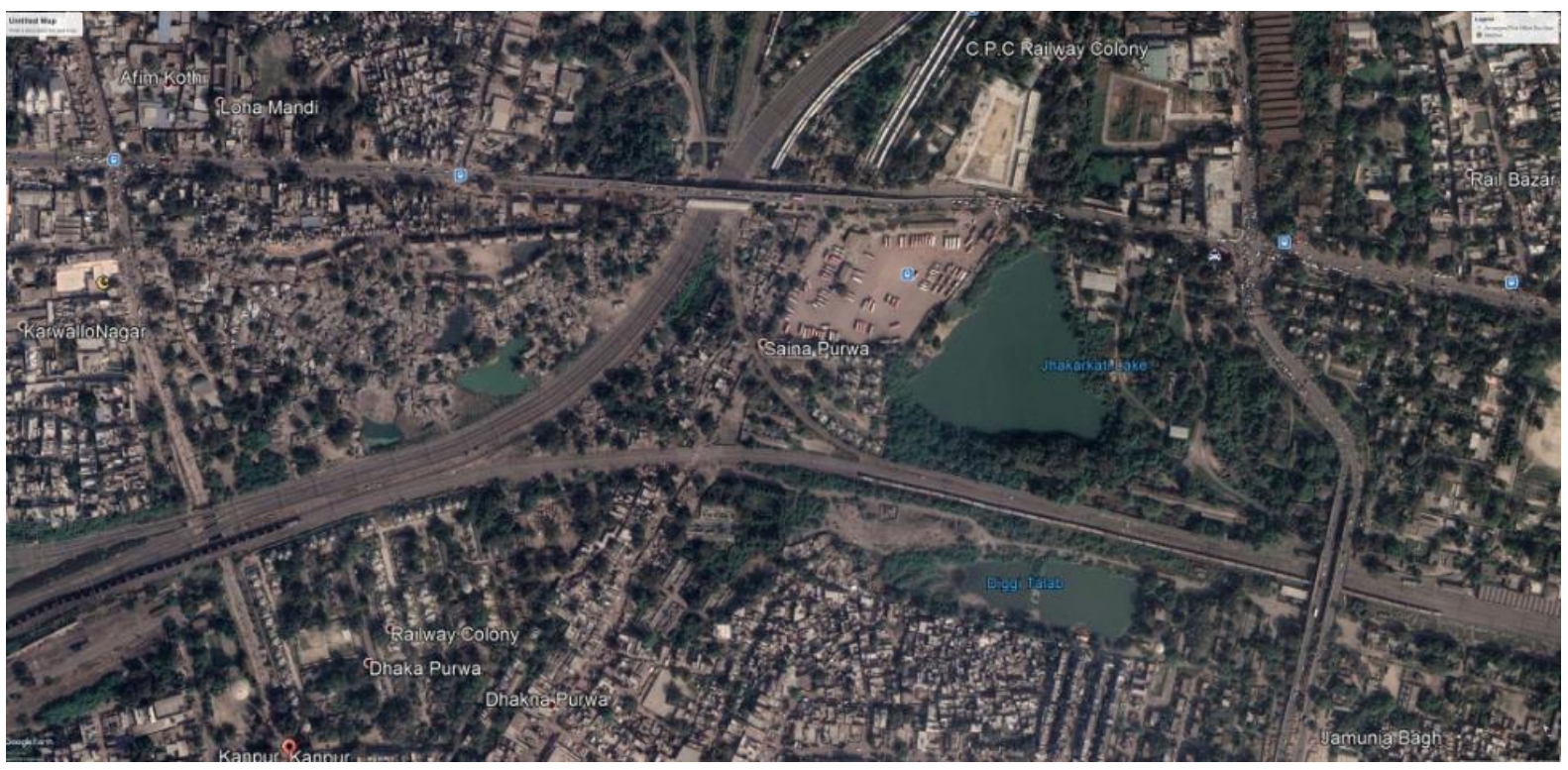

Figure 4 showcasing the google earth image of the site

The site is surrounding by major commercial centre of old city on the north which deals with wholesale market and large \& small industrial area at the north \& west which includes the abundant mill lands, Loha market, Mall godown, industrial estate. The site is entangled between the web of railway track and that is why it experiences the settlement of slums all these years because of isolated and inaccessible area on the city map. It has almost 6 slums site in and around with the population of 20000 people. The largest among them is Rakhi Mandi Basti in area and population both. Sandwiched between the underpass and flyovers, accessibility become the major problem apart of sanitation and other services.

\subsection{New proposals by the government}

There are many proposal from different agencies in this area. The major of them is underground metro station at ISBT, which will improve the connection to Kanpur Railway Station and generate a increase in footfall of communators. The other major development would be redevelopment of ISBT station in PPP model which will include a large varieties of commercial, recreational and residential activities. The Sai Purwa Basti shares the edge with the ISBT and will experience the major transformation. The other two are flyover and widening of GT Road.

All the above proposal are government and public based projects but will invite the developers for the development of land parcels. The land use plan of delineated area have major railway land as per master plan, but as per primary survey the ownership map is very different. The site is surrounded by commercial, industrial and small scale industries land use. 


\subsection{Site survey \& Demography}

\section{Demographic Data \& Building Conditions}

Kanpur, U.P., India has traditionally been an industrial city and economic center. It is been known for various small and large scale industries. City provide opportunities to the nearby areas. Around $25 \%$ of the population lives in slum. $73 \%$ of the slums have been into existence for more than 50 years in the city with old fashioned infrastructure. $36 \%$ of the total slum population is living under below poverty line (BPL) in which $75 \%$ earn less than 40 US Dollar per month.

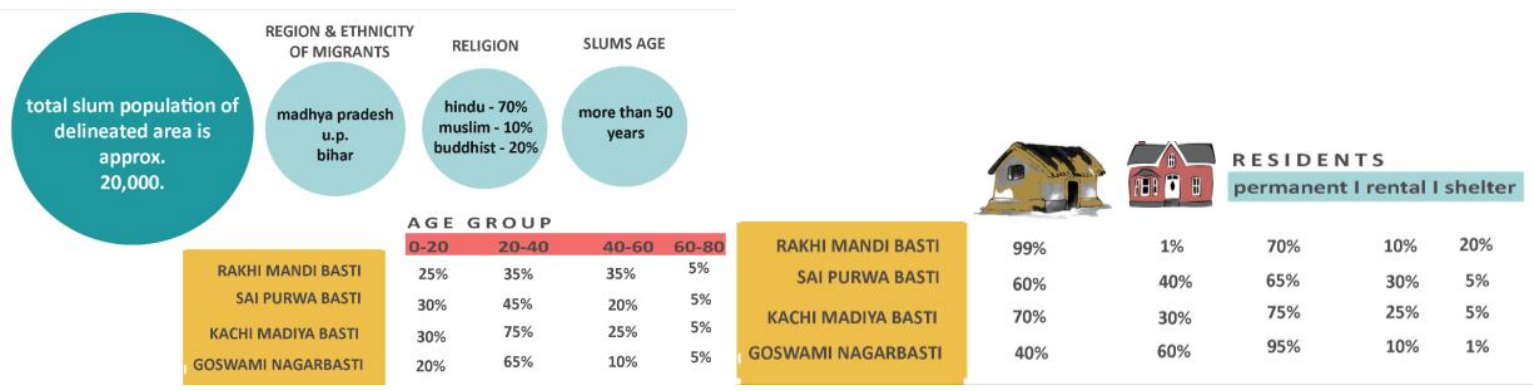

Figure 5 Tables and charts showing the documented demographics data

\section{People's perception}

For their daily routines, people living in the slums endure everyday deprivation. These unmanaged, unhealthy and unnoticed boundaries restrict themselves from many opportunity, where they have little support from any government organisations. They attempt to extend themselves over all land available to support themselves. The condition in the settlement is troubling and needs to be resolved urgently. Very few of them are able to enter the formal work structure in government jobs as clerks, gardener, sweeper etc...

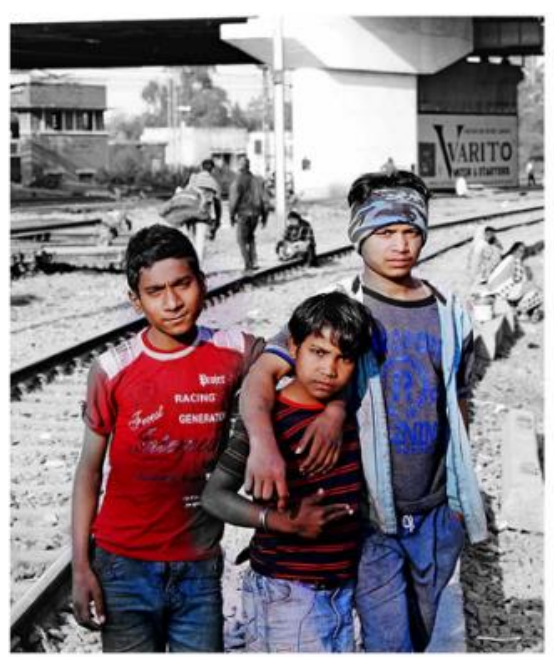

"Tracks are the only functional open spaces throughout the year rest are filled with sewage water. Its dangerous we know. "

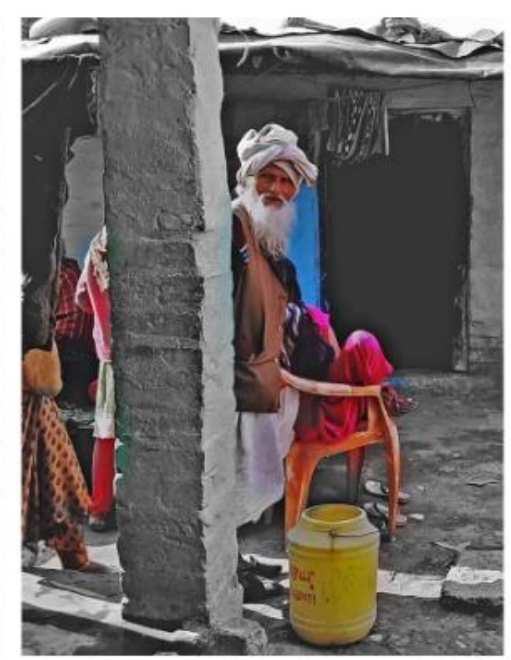

"I have been living from 70 years without no development. I wish to see something before I depart."

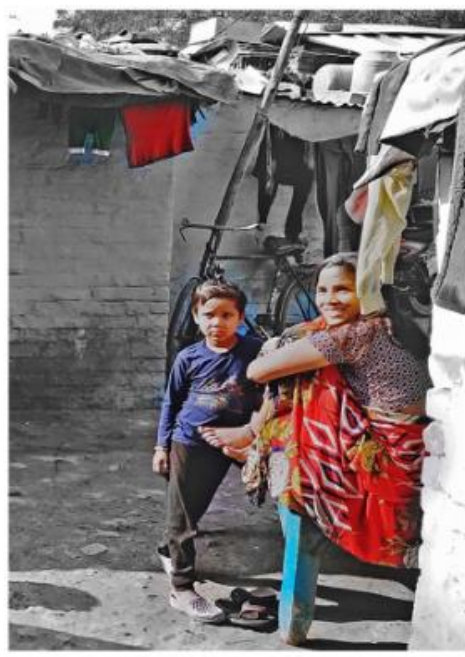

"We(females) have to wake up early at $4 \mathrm{pm}$ for open defecation and all govt. toilet complex are badly managed. "

Figure 6 People perception of the site by sharing their daily experiences. 


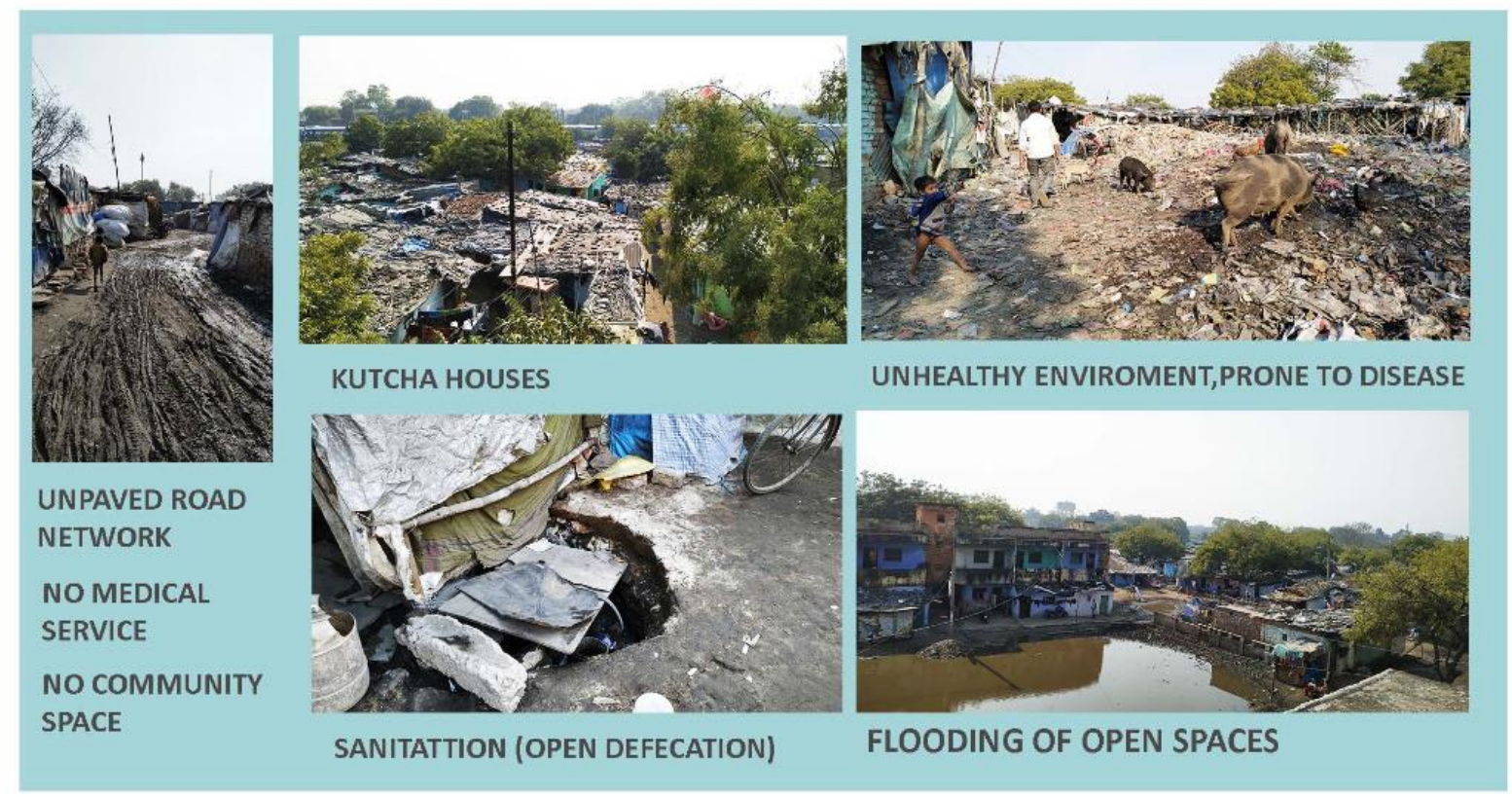

Figure 7 Pictures showcasing the site unhealthy conditions

\subsection{Ownership Pattern}

As per primary survey and report by RCUES, Hyderabad, the slum dwellers have been living here from last 75 years and were engaged in the ancillary industries to mills. The ownership of this is complex and are broadly divided into four owners. The maximum land parcel is owned by railways authority. The Rakhi mandi land has been in dispute in but as per primary data, the land belong to some old ruler.

\subsection{Livelihood pattern}

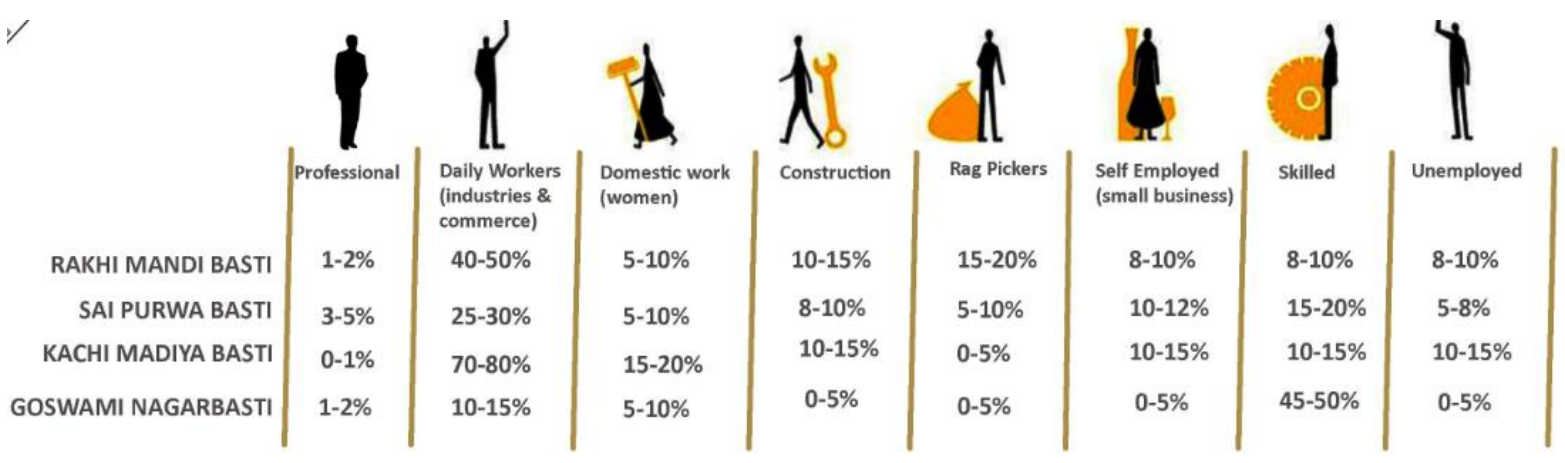

Figure 8 Graph showing the percentage of people involved in various activities for livelihood.

As per comprehensive documentation conducted on the site, it is noted that most individuals are either engaged in self-skilled based work or in nearby industrial and commercial activities as a daily worker. The average income of these individuals ranges from Rs 3000-10000 per month. Occasionally, few of the slum dwellers are working according to business requirements such as loading and unloading the goods.It is been observed that around $30-40 \%$ of people works from the site in their small businesses or manufucturing of products by utilizing the adjacent open spaces near their houses. 


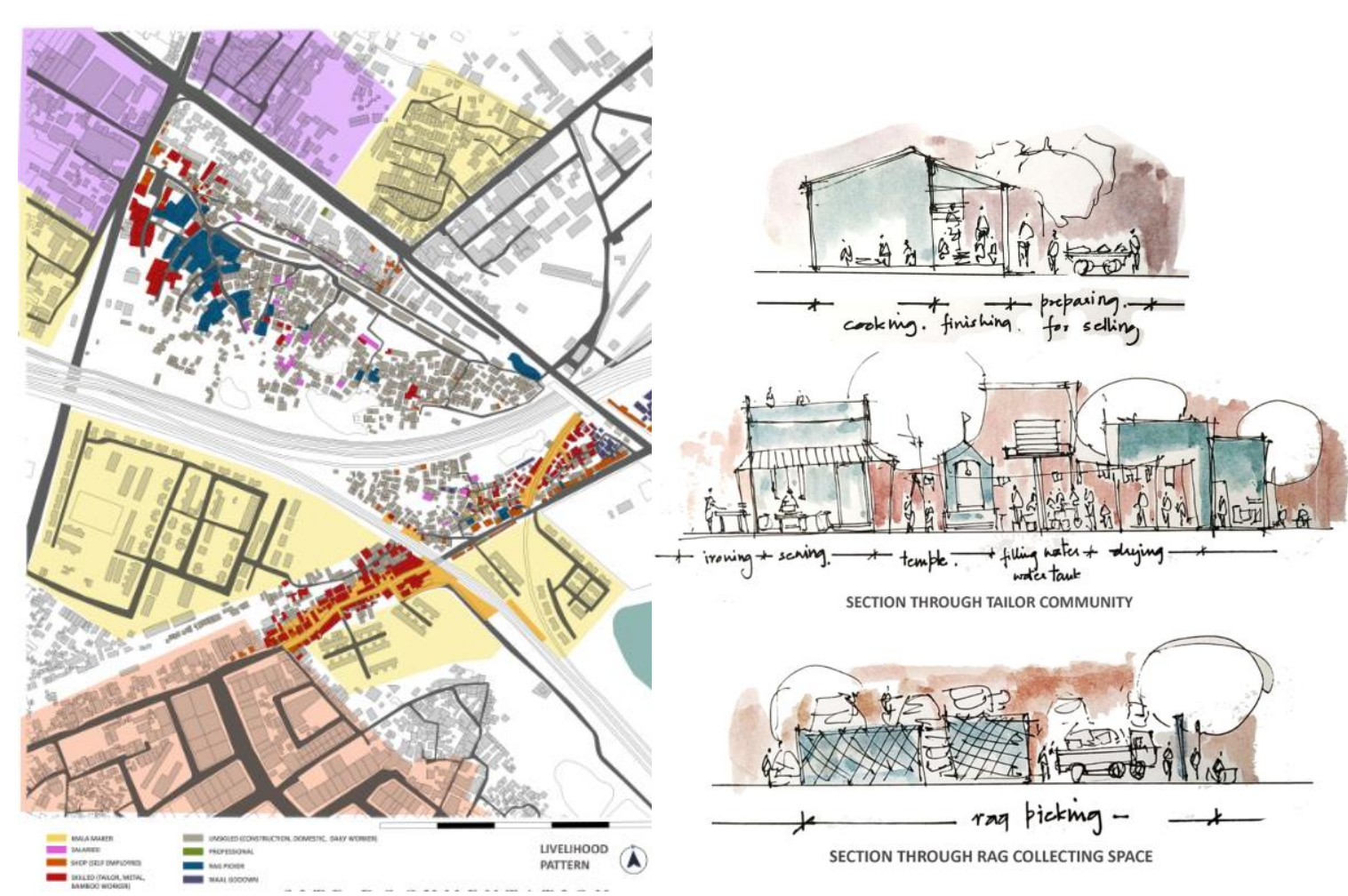

Figure 9 The detail documentation of livelihood pattern of all the slum dwellers is represented along with section showcasing the working interfaces of built and open.

\subsection{Detail workspace analysis}

In order to create sensitivity to their needs and desires, the specifics of the socio-economic-based workspace are recorded to examine the working system and space in order to explain the basic area requirements, conditions, state, shape and relationship to its habitable spaces. The people are also engaged in community based activity which requires a large space as respect to individual work areas like repair and selling of clothes, bamboo basket makers. The small and large scale workspace are near the accessible road network. Major heavy material based workspace like metal works happens close to the major running roads.
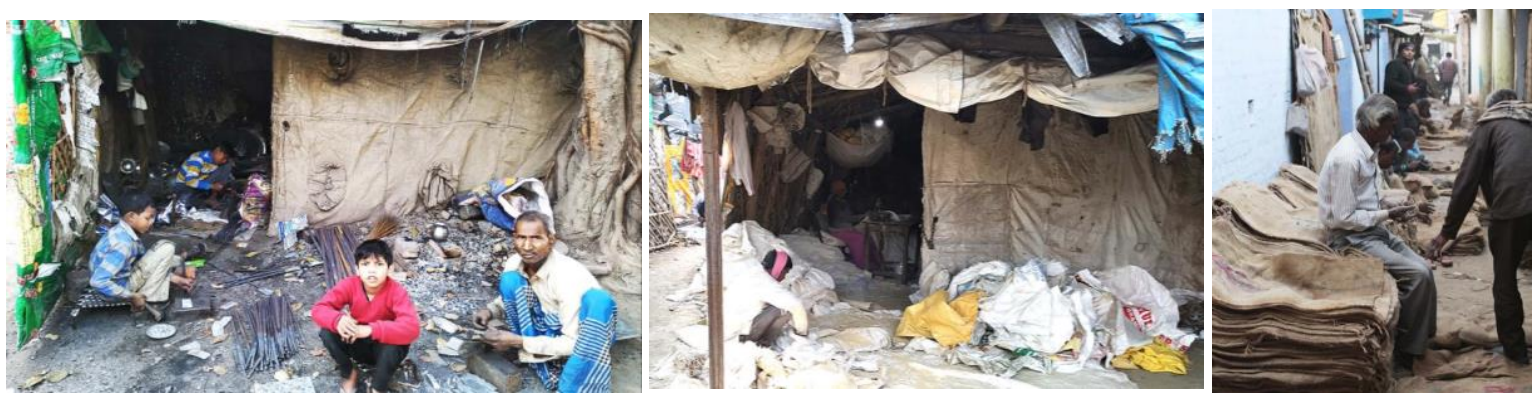

Figure 10 Picture showing the people engaged in skill based activities 

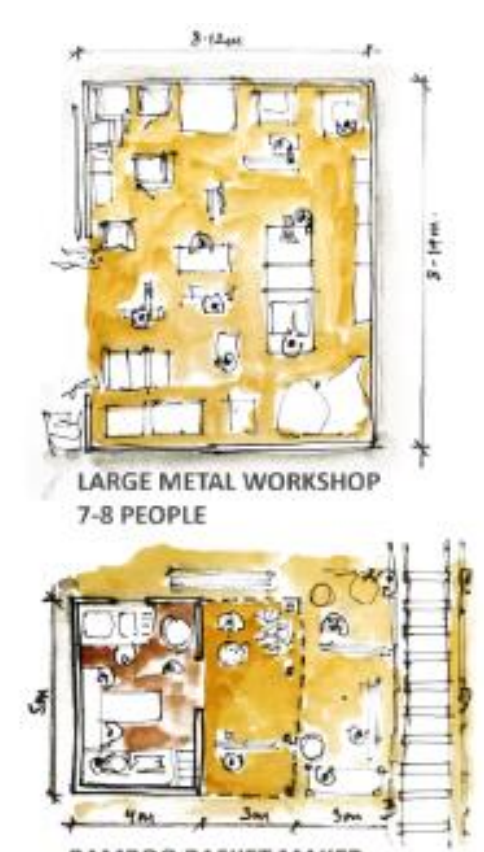

BAMBOO BASKET MAKER 7-8 PEOPLE

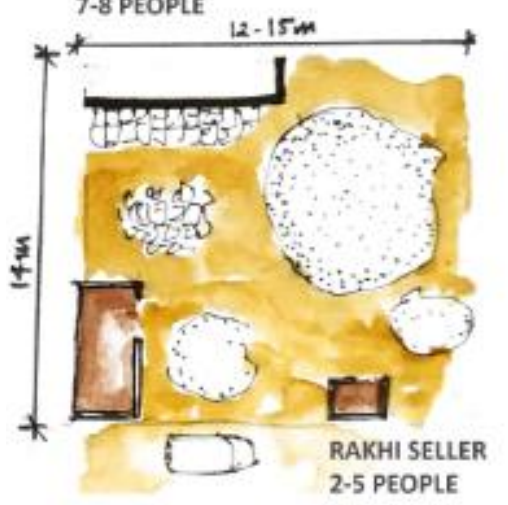

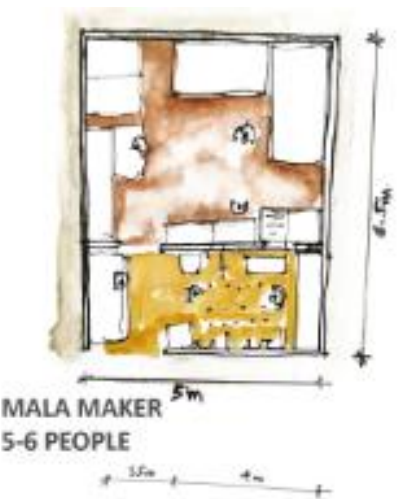
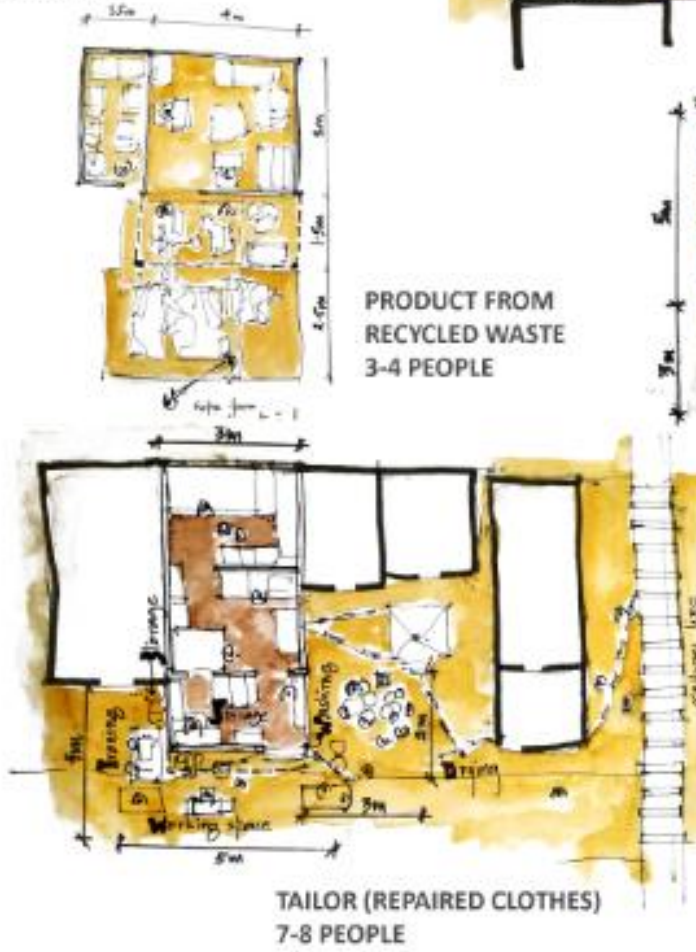
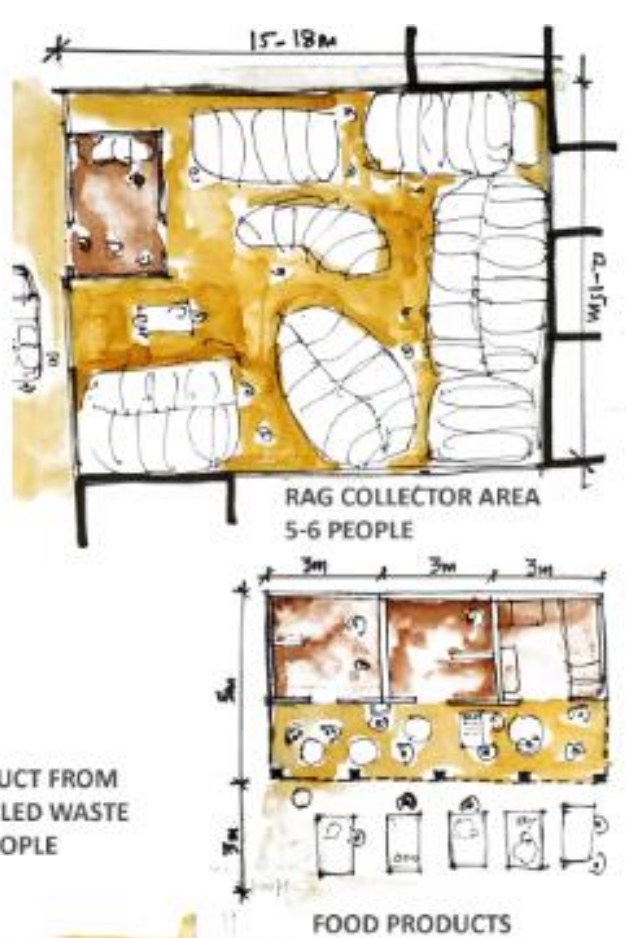

FOOD PRODUCTS 5-6 PEOPLE

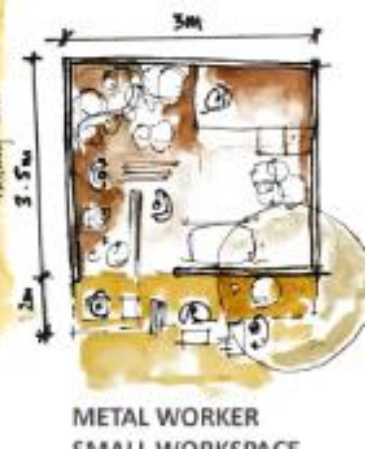

Figure 11 Plan representing the relationship between their living and livelihood spaces within site

\subsection{Movement Pattern}

The key reason for these migrants to settle at this location due to easy availability of opportunity and commute. The site which is at the middle of high commerce activities provide a number of opportunity from monthly wages to daily wages. It is been observed that the maximum movement of people happens in radial distance of $4-5 \mathrm{kms}$ from their settlement. Because of their locations and ties to major business centres, the people living in the slums have been living here for more than 50 years.

A lot of informal activities occur at major nodes and transit routes which provide interaction with range of opportunity. Due to high footfall, the informal eateries remain in great demands like breakfast, fast food, tea stalls etc. 

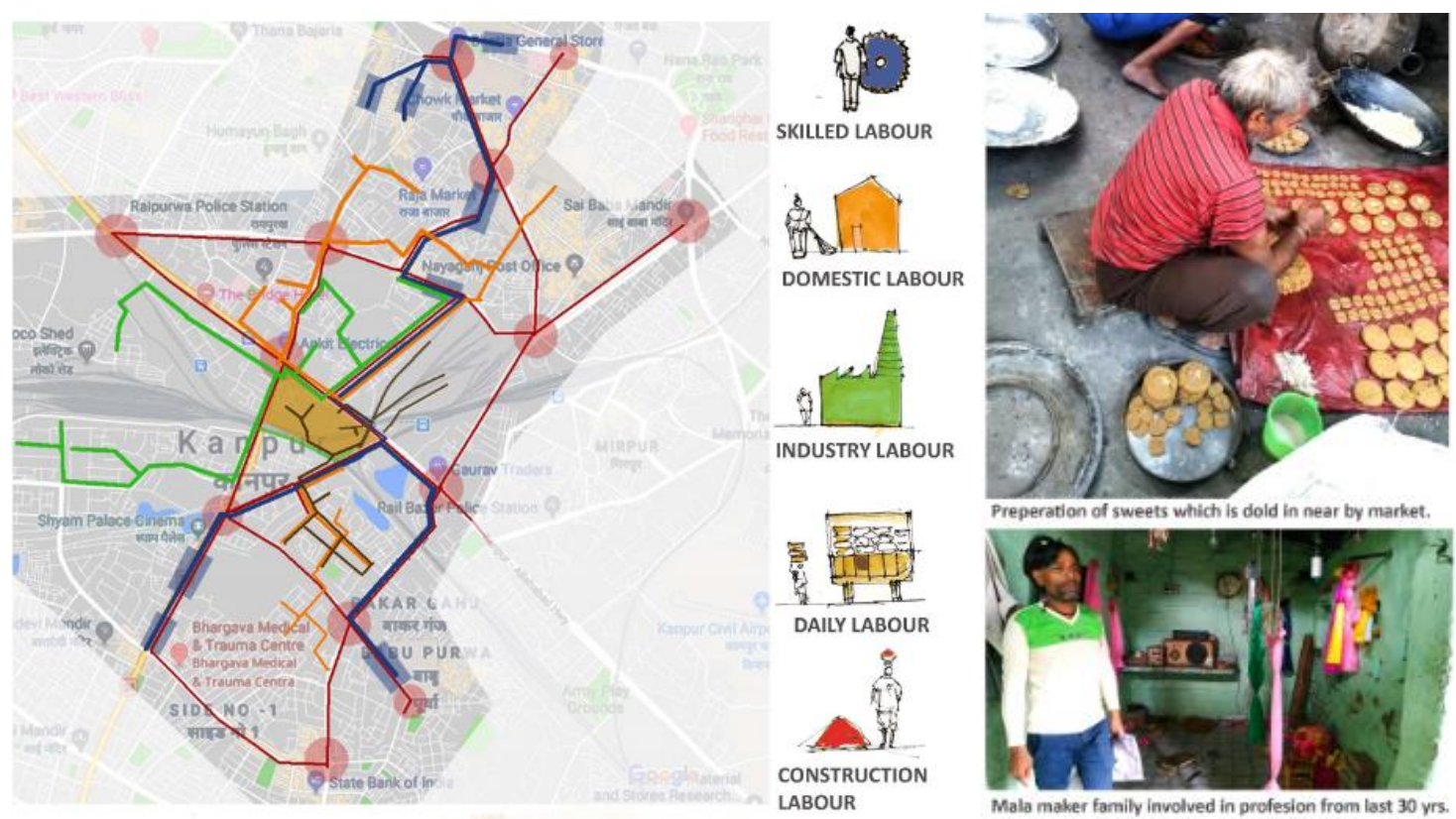

Figure 12 Map representing the movement pattern of people living in the slums for various type of activities

Many of the people involved in their self-generated small-scale industry, such as fabric makers, candy makers, mala makers, bamboo basket makers, informal food vendors, etc. it depends on the sale of their products on these markets.

\subsection{Housing Typologies}

According to the site documentation around $70 \%$ of the houses are temporary in nature. Due to site weak drainage system during monsoon, they require a lot of maintenance every year. The site comprises of majorly four housing typologies. The houses sizes are in between 250-400sqm with no toilet in the houses.

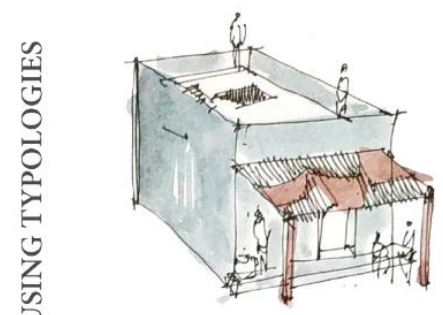

Ground Floor pucca house with temporary extension at the front.

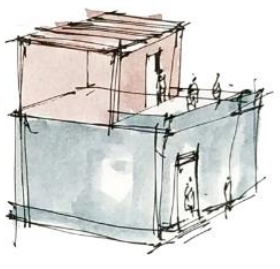

Ground Floor pucca house with extension at the first floor with temporary shade.

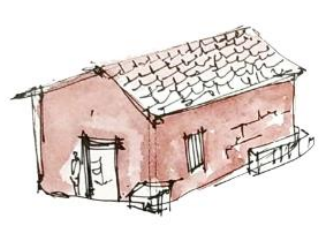

Kutch house usually made of thatch and mud and roof of clay tile or tin sheets.

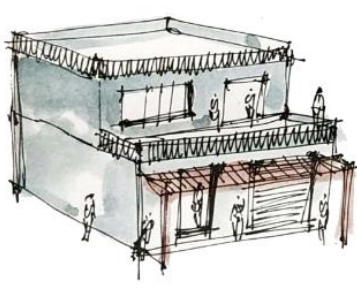

Pucca house with $\mathrm{G}+1$ floor and little extension at the front with temporary shade.

Figure 13 Different housing typologies

Spaces in these homes can only provide protection from harmful weather. Significant everyday tasks take place on a spill over or shared spaces. Since the size of the household ranges from 4 to 9 individuals in the family, it becomes difficult to fit each and every requirement of space. Apart from these permanent housing typologies, rental housing is still dominant and is needed due to seasonal opportunities for farmers during non-crop cycles. The site experiences poor quality construction, most of the materials used are obtained either by theft or used materials. 


\subsection{Open space network}

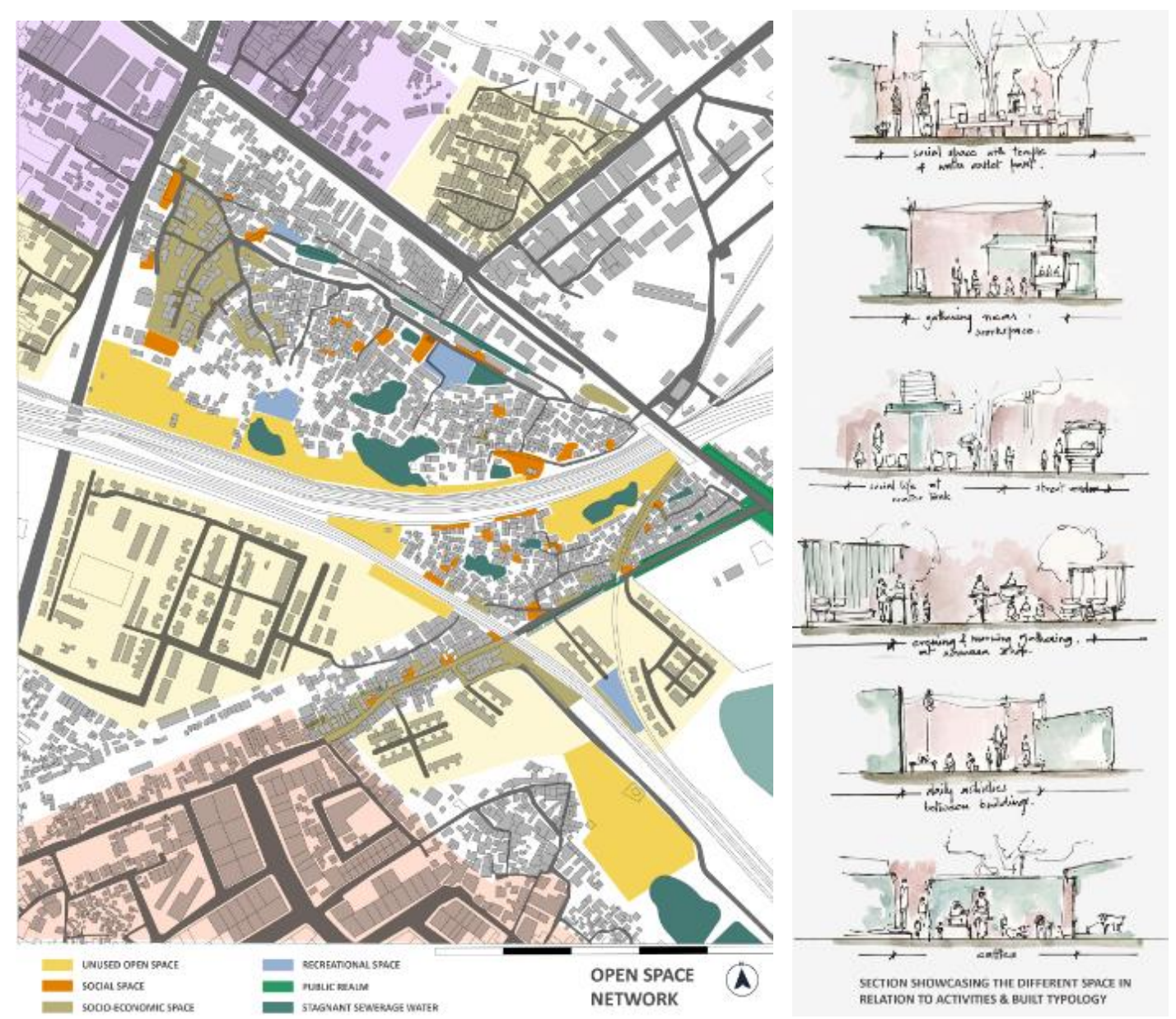

Figure 14 Map representing the nature of open spaces along with sections

The problem with the slums is that the open spaces get trapped due to inadequate drainage or open sewage system and sanitation. The open land keep flooded with the drainage \& sewage water which later becomes the root cause of health problems to the dwellers. The only social and cultural space are the tried area of the site or spaces near their houses where they are involved with the daily routines. The site has 3-4 temples or working spaces which becomes their social spaces during festivals. One major observation is that the dwellers are seen near railway track area for their daily routine because it provide a high plinth and neat area to work and play.

The active site interface is along the road network and near the railway edge due to the informal activities happening near Bus stand and G.T. Road. They are also engaged on road system for their livelihood network and activities. The open space near inactive railway track are active because it provide the large open space for continuous spread of the activities and also acts as a spill over space from the unhygienic and stagnant sewage water. 


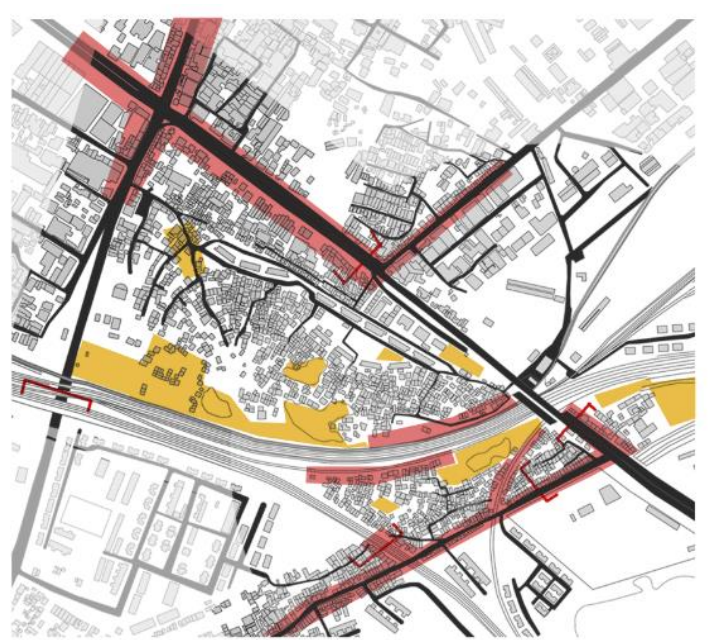

EXISTING SITE INTERFACES

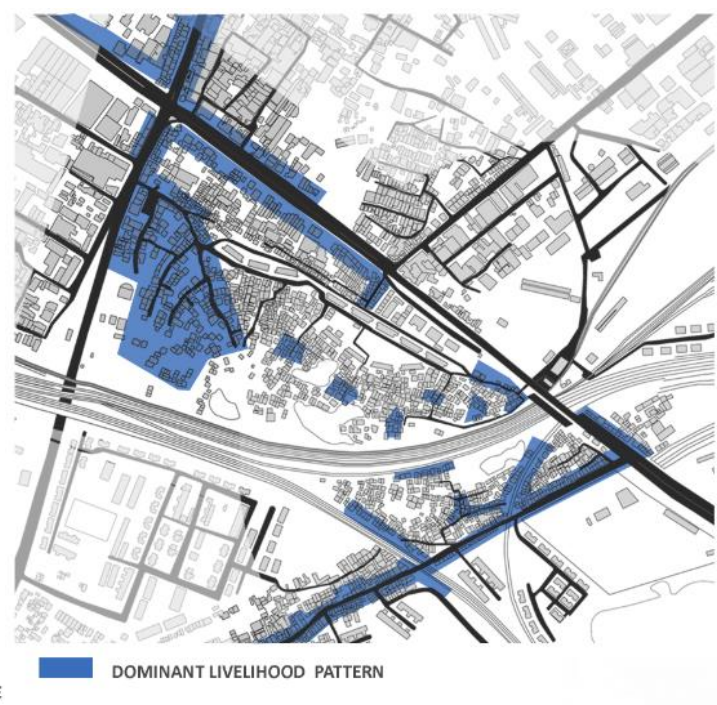

ACTIVE INTERFACE
INACTIVE INTERFACE

Figure 15 Mapping showing the active and inactive site interfaces

\section{ANALYSIS, ISSUES \& STRATEGIES}

\subsection{Existing Structure Plan}

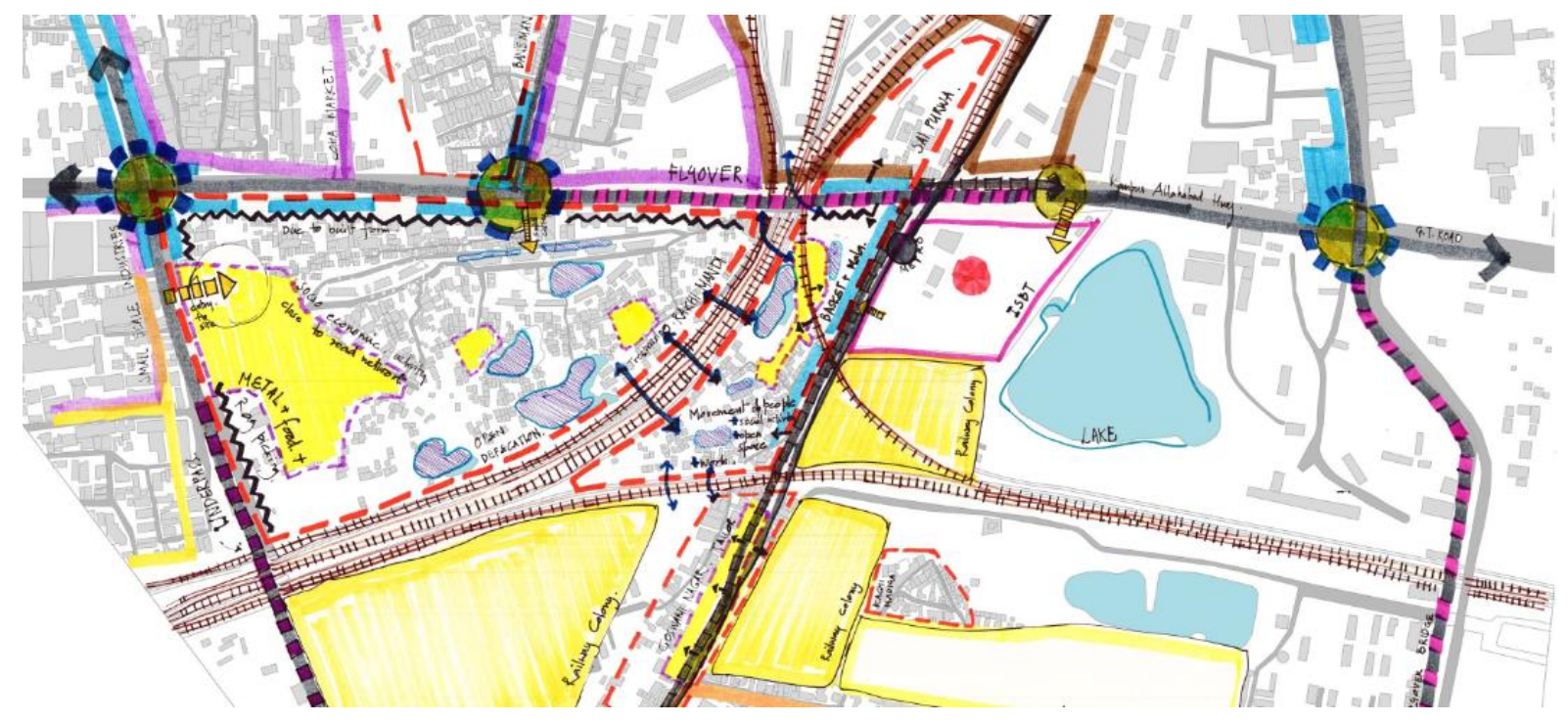

Figure 16 Site existing structure plan

The existing structure plan shows the important nodes and present important network of movement around the site area. The site has a lot of railway colony adjacent to it. The railway track acts as a barrier for movement and generates the problem of permeability and accessibility of the area, keeping it isolated from the city network. The yellow patches in the above diagram showcase the area with socio economic based activities are encountered. The site is only accessible from one or two point and it remain as a segregated parcel of land which lead to the motivation to crime, violence and unhygienic living. 


\subsection{Issues}
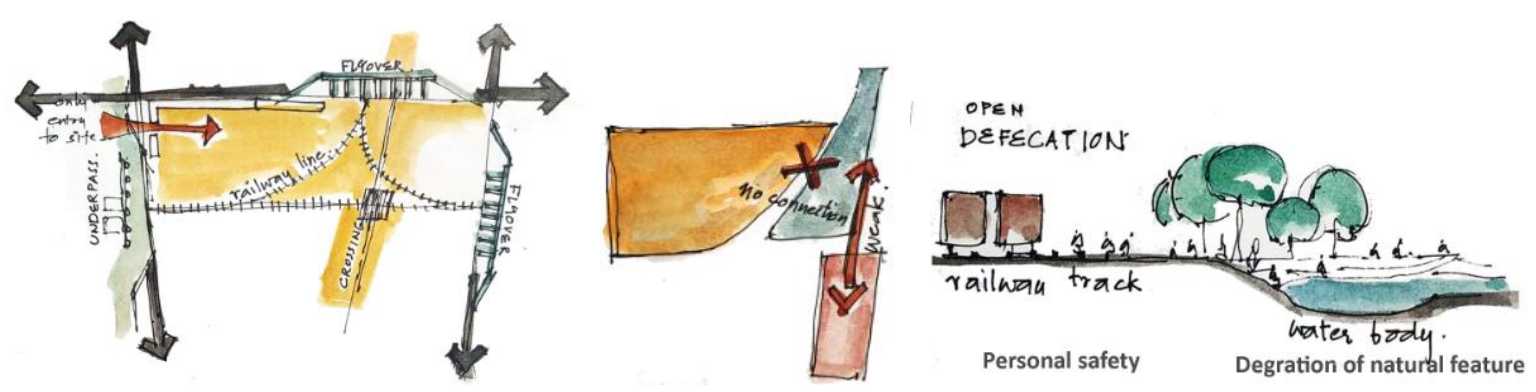

Figure 17 Sketches representing the various issues like inaccessibilty, permeability and santition issues

Due to its position between train lines, bridges and underpasses, the slum has been isolated from the city. In such instances, one of the biggest issues is accessibilty and usability. While tresspassing becomes practise over these paths for their daily routines and jobs due to no official road network between these slums. The cross is like messing up with their lives, over them. Owing to the exchange of their cultures, customs and traditions, there is a need to integrate these slums.

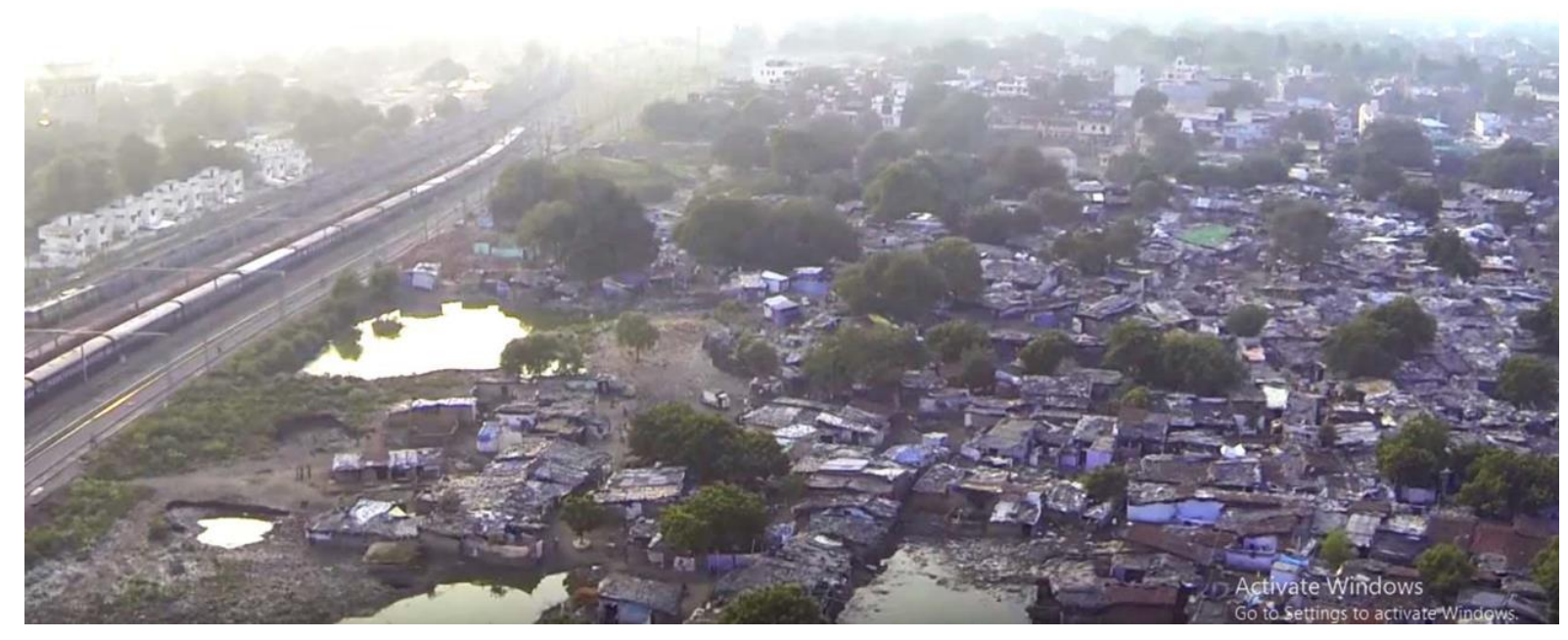

Figure 18 Aerial photograph showing the side edges

Many slums do not have a toilet in their homes and rely on open defecation near existing stagnent water edges resulting in poor water quality and unhygienic condition which becomes breeding grounds for diseases and hence degradation the habitable environment. Many incidents of female haressment cases have also been reported in the area for the same cause.

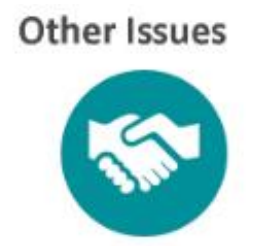

OPPORTUNITIES

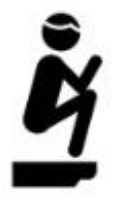

HYGIENE

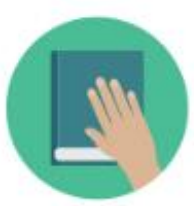

EDUCATION

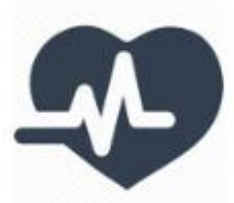

HEALTH

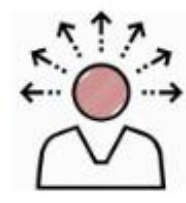

AWARENESS

Figure 19 Other major issue faced by the residents of the slums. 


\subsection{People's aspiration}

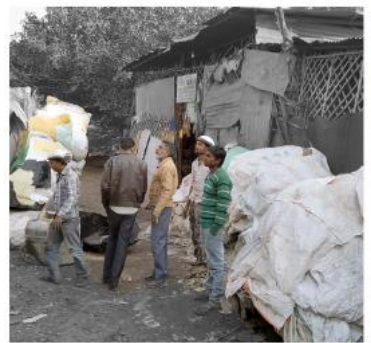

"If we could compress and process the waste, we could have minimize the space requirement and earn more money."

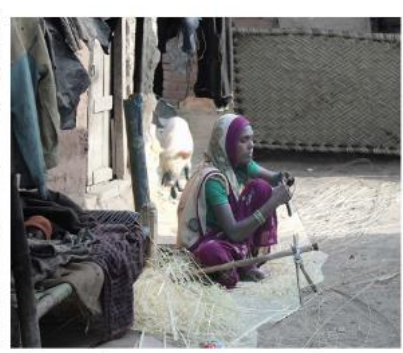

"I can make more products out of bamboo if given a chance. We(family) are doing htis from last 100 years. we belong to Rewa, M.P.

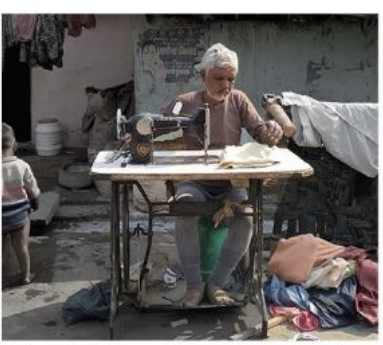

"We look forward to the formal working space, where we can grow \& earn more like others. I would like to open my own shop."

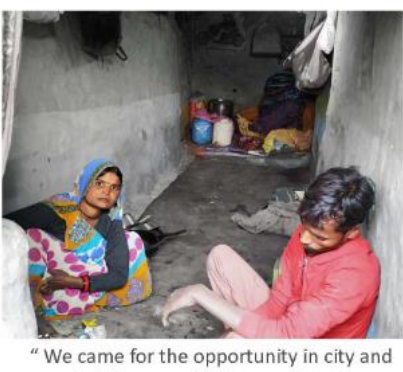

"We came for the opportunity in city and space."

Figure 20 People's aspiration to get involved into formal system

Through improving their abilities, jobs and infrastructure, the residents of the slums hope to have greater economic security. By being a member of the city's formal system, they look forward to raising their standard of living. The lack of space and basic facilities holds them back with intense depression and daily hardships.

\subsection{Inferences}

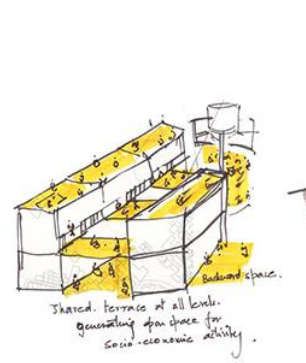

QUALITY HABITATION

Increasing the quality of habitable space with additional floor space to cater to their requirement.

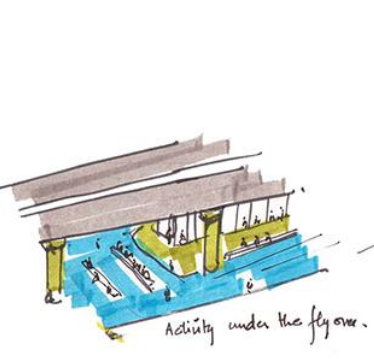

LAND UTILIZATION

Utilization of all the land parce which were unused because of physically and visually connectivity. Eg. Places under flyover, near railway land etc.

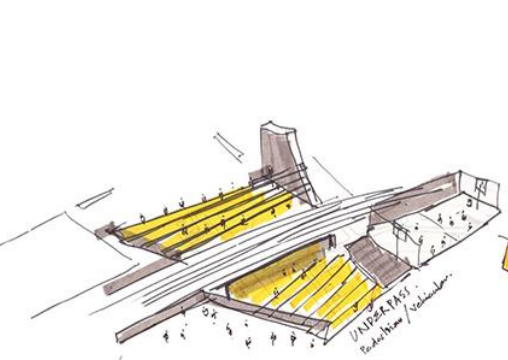

ACCESSIBILITY

Increasing the accessibilty between the site through underpass and adding to city network.

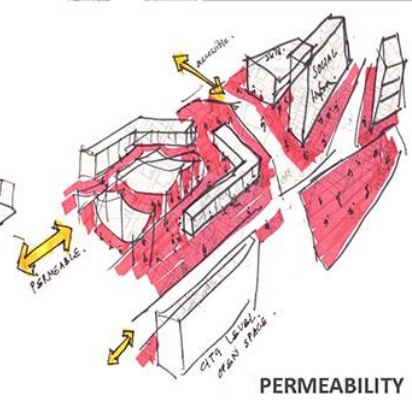

Trying to generate the physical and visual permeability through principle of urban design \& design.

Figure 21 Major focus areas to generate an inclusive urban environment with formal and informal edges

\subsection{Strategies}

After analysis the cases, it is been observed that the government lacks the holistic approach for the development. The general practice involves the development on the basic of numbers and quantities to be achieved. But we need to understand that if the development is not seen as a self-sustaining model, we will end up making planned slums where the people will never able to achieve good quality of life. A habitation also deals with the environment in which they occupies their daily routines and cultures. A good combination of open spaces, social infrastructure, opportunity, livelihood and accessibility together can lead to the self-maintained and sustained neighborhood. 


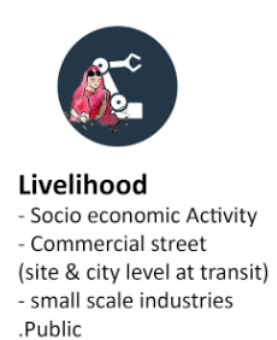

Public
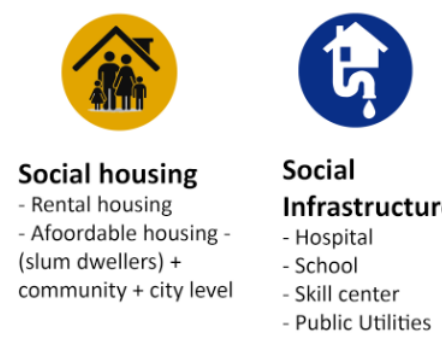

Social Infrastructure

- Hospital

- School

- Skill center

- Public Utilities

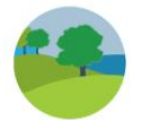

Open Space

Community level space

neighbourhood space

City level open space

- Public Space (transit)

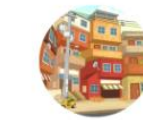

City Connectivity

(Accessibility)

- Strengthen Road Network - Formal \& Informal edge

- City Level Activity

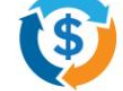

Financial, approach

for development

Housing (affordable)

Commercial Use

Industrial Use ( smal

scale)

- Informal vendors

- Public Utilities

Figure 22 Spatial strategies for holistic development

\section{Livelihood}

Slum dwellers' livelihoods rely heavily on the everyday routine and the space they use. Many individuals are engaged in events in which they use the common room with the house and in which the family is often involved in the method of living. The creation should also work on the principle of living, working and playing focussed on the development of socio-economic community based activities and provide people with jobs in the workshop area, shops and nearby informal vending zone.

\section{Social housing}

The biggest problem is to preserve the slum dwellers' relationship between shelter and subsistence. It is important to comply sensitively with the recovery of the site's performers. The slum's open space connection to the recovery block should provide them with architecture and space versatility. The planning should concentrate on the possibilities of designing a housing scheme that delivers on the conditions of time and space.Introduction to new housing system like rental, time based, leased based etc. should be exolpred to provide flexiblity to the new migrants in the city.

\section{Social Infrastructure}

The major part of empowerment hold on to this area. Any habitation needs social infrastructure to uplift and empower themselves. And infrastructure to such section of society is the prime need of concern. The idea of social urbanism talks about dealing with such ideas of involvement and innovation in the city. In similar case, the project should always talk about the engagement of people to the self development system through training and learning from the resources. A skill development centre would help to build the skilled human resource for the city which in return would empower the slum dwellers in and around the city. As Kanpur is an industrial city and it is engages people in alot of large and small scale industrial work and business. The trained crowd will help to develop more individual engagement in such fields. Along with that the other such as library park, school, computer centre, hospital, anganwadi etc will help to promote awareness of such things in the communities.

As an urban designer, it is necessary to understand the need of the people and city's context and potential to do justice to design through ideas and innovations. The location of such social infrastructure is also necessary to maximize the potential of built form and space. The idea is to utilize the central space of any site to generate the major activity which would bridge the gap between the formal and informal edge. Like case of Medellin, the skill centre is designed with strong architectural character along with $t$ the proper fore ground for strong visibility and usability during events and activities.

\section{Open space}

The open space plays a very vital role in generating a physical, cultural, economic and psyological need of an individual. The open space offers an incentive to get involved in socio-economic practises focused on society scattered over their house and street interfaces, such as the weaver of bamboo basket 
community. Along with just habitation, it is very much required to understand the their everyday interaction in the open spaces from residential unit to neighbourhood edges. The spaces like balcony, corridors, incremental spaces, spaces between buildings, parks, informal activities space etc. is utilized as spill over spaces to accomadate the daily activities. So, it is important that for every project the open spaces are designed at three stages:

1. The city connected edge at the site.

2. The space at the housing level for carrying out socio economic activities.

3. Incremental spaces at immediate interface.

\section{Accessibility (City Connectivity)}

The key issue of isolation stems from the weak accessibility and permeability of the environment. In those areas that are ignored and merely visited, experiences the same sort of problem or formation. Abuse, crime and toxic conditions are part of these regions. In order to get the region back to the city map, extreme design solutions have to be tackled in order to facilitate access, movement and connectivity.

\section{Actions}

Actions to be taken at three levels to get the holistic approach towards getting the healthy and inclusive environment.

Micro - To rehabilitate, repair and upgrade the built environment through human centered approach

- Development of different housing model.

- Improving the image of slum rehab. Projects.

- $\quad$ Providing with the flexibility of space for their livelihood by taking incremental housing approach.

- $\quad$ Exploring the housing model for investors.

Meso - To reinforce and strengthening the public space by upgrading the social economic community life.

- Intervention of micro \& meso level open space.

- $\quad$ Enhancement of small scale industries.

- $\quad$ Providing with strong social infrastructure catering to neighborhood \& city level.

- $\quad$ Structuring the settlement and city edge.

Macro - To restructure and reconnect the social, economic and physical gap between formal and informal city system

- $\quad$ Blending of formal and informal edges.

- $\quad$ City level open spaces to incorporate activities.

- Enhancing the permeability and accessibility.

- Making the important nodes as part of connected transit system 


\section{Impact}

- De-stigmatization toward the slum dweller.

- Generating the new beautiful imagine to the city.

- Making the part of public edge \& utilizing land for development.

- Providing them with designed neighborhood.

\section{Conclusion}

Holistic approach plays an important role and is strongly based on the community participation and the social component. The issue should be analyzed and addressed in three levels of interaction in urban environment from micro to macro. Physical and visual accessibility plays a very important role in determining the inclusivity. Transformation is based on the understanding of the socio-economic fundamentals, spatial pattern and the community-oriented planning rather looking as real estate finance lens. These livelihood factors plays an important role in shaping of the environment.

\section{References}

AUTHORITY, K. D. (n.d.). Kanpur master plan 2021.

Camillo Boano, W. H. (n.d.). contested Urbanism.

habitat, u. (2015). A Practical Guide to Designing, Planning, and Executing Citywide Slum Upgrading Programmes .

Harvey, D. (n.d.). Right to the City.

INSTITUTE, M.-D. (n.d.). Brief Industrial Profile of District Kanpur Nagar.

KENTON, W. (n.d.). behavioural economics.

Malandrino, C. (2017). On the "Medellin Miracle" and the "Social Urbanism" Model.

parekh, H. (n.d.). Slum networking of indore city.

Prychitko, D. (n.d.). Marxism. the library of economics \& liberty.

RCUES, h. (n.d.). Slum Free City Plan of Action - Kanpur.

Sinha, A. (n.d.). kanpur, machester of east. 